\title{
What restricts generative rejuvenation of Calluna vulgaris in continental, dry heathland ecosystems: seed production, germination ability or safe site conditions?
}

\author{
*,** Katrin Henning, ${ }^{* * *}$ Goddert von Oheimb \& "Tischew Sabine \\ *Anhalt University of Applied Sciences, Department for Nature Conservation and Landscape Planning, \\ D-06406 Bernburg, Germany; \\ ${ }^{* *}$ Leuphana University of Lüneburg, Faculty of Sustainability, D-21335 Lüneburg, Germany; \\ *** TU Dresden, Faculty of Ecology and Nature Conservation, D-01062 Dresden, Germany, \\ e-mail: k.henning@loel.hs-anhalt.de
}

\begin{abstract}
A large-scale field experiment with different management options (free-range grazing, onetime cutting, additional disturbances and their interactions) was carried out in a continental, dry heathland. Within the framework of the experiment seed production and germination ability of over-aged Calluna individuals as well as specific safe site conditions were investigated to reveal restricting factors for the generative rejuvenation of Calluna. The calculated values of seed production and germination ability of over-aged Calluna individuals can be compared with those from literature or exceed the values reported there. Therefore, seed production and germination ability are not the limiting factors for the generative rejuvenation of Calluna. Free-range grazing with large herbivores combined with onetime cutting of over-aged Calluna stands supports the generative rejuvenation, especially due to the creation of specific safe sites, which are crucial for a successful survival of Calluna seedlings. Particularly a light shadowing seems to be the restricting factor for a successful generative rejuvenation of Calluna in continental, dry heathlands.
\end{abstract}

Key words: disturbance, free-range grazing, germination, management, seedling establishment.

\section{Introduction and study area}

Heathlands at the edge of their ecological distribution (eastern, continental region) are often heavily degraded by an over-aging and the absent or limited generative rejuvenation of C. vulgaris (Sedláková \& Chytrý, 1999; Valbuena et al., 2000) due to land abandonment and changing environmental conditions. Still, there is a lack of knowledge of driving factors, which restrict and promote the generative rejuvenation of Calluna and regenerate over-aged heathlands in continental climates. Therefore, a large-scale field experiment in an abandoned former military training area in Eastern Germany (Oranienbaumer Heide) with free-ranging cattle and horses was implemented to test their effects on over-aged Calluna populations in heaths and mosaics with dry basophilic grasslands. In addition, combinations with a onetime cutting management and additional disturbances were tested. Furthermore, seed production and germination ability of over-aged Calluna individuals as well as essential safe site conditions were examined as potential limiting factors for the generative rejuvenation.

\section{Research methods}

The effects of grazing, cutting, disturbances as well as their interactions were investigated on $5 \mathrm{~m}$ x $5 \mathrm{~m}$ plots using a multi-factorial block experiment with an integrated splitplot design. Grazing was realized by the basic management in the study area. Cutting was done once with a brushcut- 
ter on a level of 3-5 cm over ground. The cutted material was removed from the plots. On the half of each plot (sub-plot) 25 randomly selected additional disturbances $(10 \mathrm{~cm} \times 10 \mathrm{~cm})$ were applied by removing the litter and humus layer by hand. The disturbances imitate the trampling effects by cattle and horses and mimic a higher grazing pressure. Seed production was estimated on sub-plot level by collecting all flowering shoots of the over-aged Calluna individuals within 96 quadrats $(50 \mathrm{~cm} \times 50 \mathrm{~cm})$ at the time of the highest seed maturity. Germination ability of seeds was examined depending on different life cycle stages of Calluna and stratification in a growth chamber. The in situ germination and establishment of Calluna seedlings was investigated on sub-plot level twice a year on the basis of the following eight parameters: distance to the nearest adult Calluna individual, shadowing, exposition, position, root competition, proportion of bare ground, soil without vegetation as well as coverage ratio of vegetation. All data were processed and analysed using statistical package IBM SPSS statistics (version 19, IBM Corporation 2010) or R (version 3.0.2, R Development Core Team 2013), using the package lme4 (Bates et al., 2014). The measured data were tested for normality and homogeneity of variance using a one-sample Kolmogorov-Smirnov test and Levene's test. The statistical analysis of seed production and germination were carried out with one-sample t-tests or one-way analyses of variance (ANOVAs). Percentage data were arcsine transformed to achieve normality prior to the ANOVAs and t-tests being performed. The effects of treatments and safe site conditions on the survival of Calluna seedlings were analysed separately by using generalized linear mixed models (GLMMs) with a binomial error term, fitted by maximum likelihood. Grazing, onetime cutting, additional disturbances as well as safe site conditions were included as fixed effects. Plot was included as a random effect to account for the split-plot design of the experiment.

\section{Results}

Seed production per $\mathrm{m}^{2}$ of over-aged Calluna stands was extremely variable, ranging from 139639 to 760451 (mean: 340770 seeds $\mathrm{m}^{-2}$, SD: 122 872.59). The mean germination rates depending on life cycle stage and stratification ranging between $62 \%$ and $78 \%$ but life cycle stages of Calluna did not affect seed germination significantly. The stratification had a significant effect on the germination of Calluna, showing higher germination rates for stratified seeds during the first 15 days. In Calluna dominated stands highest seedling germination and establishment was observed on plots with the combination grazing, cutting and additional disturbances (Table 1). But also all other treatments that included additional disturbances (mimicking a higher grazing pressure) showed higher occurrences of Calluna seedlings than plots without these treatment. Additional disturbances and safe site conditions (i.a. light shadowing, high proportion of bare ground) significantly supported the survival of Calluna seedlings in Calluna dominated stands (Table 2). In mosaics of heather and dry basophilic grasslands the combination of grazing and cutting showed highest seedling occurrence, but no significant effects on the germination and survival of seedlings between the different treatments were observed (Table 1). The generalized linear mixed model indicated that only shadowing significantly affected the survival of seedlings within the mosaics (Table 2).

Table 1. Mean values and standard deviations (in brackets) of seedlings and juveniles recorded per $12.5 \mathrm{~m}^{-2}$ plot during one growing season. Significant differences for germination are indicated by an asterisk ${ }^{*} p<0.05,{ }^{* *} p<0.01$. Treatments: $G=G r a z i n g$, $\mathrm{C}=$ Cutting, $\mathrm{D}=$ Disturbances, $0=$ Control

\begin{tabular}{lcccc}
\hline \multirow{2}{*}{ Treatment } & \multicolumn{2}{c}{ Calluna dominated stands } & \multicolumn{2}{c}{$\begin{array}{c}\text { Mosaics of heather and dry } \\
\text { basophilic grasslands }\end{array}$} \\
\hline & seedlings & juveniles & seedlings & juveniles \\
\cline { 2 - 5 } G & $8.2(12.3)$ & $6.7(9.2)$ & $2.2(2.6)$ & $2.2(2.6)$ \\
GxC & $8.7(17.4)$ & $8.2(17.2)$ & $7.2(12.3)$ & $5.7(9.6)$ \\
GxD & $50.3(51.9)^{*}$ & $48.2(49.3)$ & $0.7(1.0)$ & $0.7(1.0)$ \\
GxCxD & $67.5(62.2)^{*}$ & $65.0(60.2)$ & $1.2(1.6)$ & $1.2(1.6)$ \\
CxD & $38.4(30.1)^{*}$ & $35.8(30.0)$ & $4.2(5.3)$ & $4.2(5.3)$ \\
$\mathrm{C}$ & $12.0(28.9)$ & $9.7(23.7)$ & $1.0(2.4)$ & $1.0(2.4)$ \\
$\mathrm{D}$ & $41.5(36.4)^{* *}$ & $40.2(36.5)$ & $1.2(1.6)$ & $0.7(0.8)$ \\
0 & 0,0 & 0,0 & $4.7(6.9)$ & $3.5(5.2)$ \\
\hline
\end{tabular}


Table 2. Generalized linear mixed models (GLMM's) for treatment and safe site condition effects on the survival of Calluna seedlings in Calluna dominated stands and mosaics of heather and dry basophilic grasslands during 1 growing season $(n=6)$. Significant differences for survival are indicated by an asterisk ${ }^{*} \mathrm{p}<0.05,{ }^{* *} \mathrm{p}<0.01,{ }^{* * *} \mathrm{p}<0.001$

\begin{tabular}{|c|c|c|c|c|c|c|c|c|}
\hline \multirow{2}{*}{$\begin{array}{l}\text { Treatments / } \\
\text { Safe site conditions }\end{array}$} & \multicolumn{4}{|c|}{ Calluna dominated stands } & \multicolumn{4}{|c|}{$\begin{array}{c}\text { Mosaics of heather and dry } \\
\text { basophilic grasslands }\end{array}$} \\
\hline & Estimate & Std.Erro & z-value & $\operatorname{Pr}(>|z|)$ & Estimate & Std.Erro & z-value & $\operatorname{Pr}(>|z|)$ \\
\hline (intercept) & 3.13 & 0.65 & 4.79 & $<0.001^{* * *}$ & 9.83 & 6.20 & 1.58 & n.s. \\
\hline Grazing & 0.20 & 0.65 & 0.31 & n.s. & -1.52 & 8.71 & -0.18 & n.s. \\
\hline Onetime cutting & -0.78 & 0,66 & -1.18 & n.s. & 0.01 & 8.63 & 0.00 & n.s. \\
\hline Additional disturbances & 0.80 & 0.25 & 3.25 & $<0.01^{* *}$ & -2.07 & 2.63 & -0.79 & n.s. \\
\hline (intercept) & -0.87 & 1.66 & -0.52 & n.s. & 19.37 & 25.67 & 0.75 & n.s. \\
\hline Shadowing & 4.83 & 0.35 & 13.72 & $<0.001^{* * *}$ & 5.91 & 2.62 & 2.26 & $<0.05^{*}$ \\
\hline Exposition & -0.22 & 0.07 & -3.13 & $<0.01^{* *}$ & -1.10 & 1.08 & -1.02 & n.s. \\
\hline Soil without vegetation & -0.03 & 0.01 & -2.51 & $<0.05^{*}$ & -0.36 & 0.26 & -1.42 & n.s. \\
\hline Bare ground & 0.05 & 0.03 & 2.12 & $<0.05^{*}$ & -0.02 & 0.17 & -0.13 & n.s. \\
\hline Position & -0.24 & 0.17 & -1.46 & n.s. & -0.66 & 2.27 & -0.29 & n.s. \\
\hline Distance & 0.01 & 0.02 & 0.88 & n.s. & 0.29 & 0.16 & 1.86 & n.s. \\
\hline Root competition & -0.11 & 0.17 & -0.67 & n.s. & 1.47 & 1.28 & 1.14 & n.s. \\
\hline Vegetation coverage & 0.01 & 0.01 & 1.17 & n.s. & 0.12 & 0.31 & 1.21 & n.s \\
\hline
\end{tabular}

\section{Discussion}

Seed production of over-aged Calluna individuals originating from the continental study area was comparable high as in Atlantic regions and was even as high as seed production found in earlier life cycle stages of Calluna or exceeded the values reported there (Cummins \& Miller, 2002; Piessens et al., 2005). The high percentage and rate of germination of Calluna seeds under controlled conditions is also in agreement with previous studies from Atlantic as well as continental sites (Pons, 1989; Vera, 1997). Free-range grazing seems to be a suitable management tool to support Calluna rejuvenation due to the creation of safe sites for seedling establishment. Especially a light shadowing of Calluna seedlings supports the germination and the survival of them in continental regions. Therefore it is essential to create and maintain a heterogeneous vegetation structure in dry heathlands, which is supported by grazing anyway (Bokdam \& Gleichman, 2000). A higher grazing pressure, mimicked by additional disturbances, lead to an increase creation of safe sites (Mitchell et al., 2008; Newton et al., 2009). In the naturally high presence of bare ground and light availability caused by lower vegetation cover, a low stocking rate is adequate to maintain patchy mosaics of heather and dry basophilic grasslands. In dense, over-aged Calluna-dominated stands a higher grazing pressure is necessary to increase the proportion of bare ground and light availability, which lead to a higher germination and survival of Calluna seedlings. Onetime cutting leads to a temporarily and locally higher grazing pressure due to the enhanced preference and digestibility of re-sprouted Calluna shoots by the grazing animals (Lake et al., 2001) and consequently supports the rejuvenation of Calluna. Finally it can be stated, that even over-aged Calluna individuals are able to produce high quantities of seeds, which further show high germination rates. According to this, seed production and germination ability of seeds of over-aged Calluna stands are not the restricting factors for the generative rejuvenation. Safe site conditions are crucial and the limiting factor for the successful establishment and survival of Calluna seedlings.

\section{References}

Bates D., Maechler M., Bolker B. \& Walker S., 2014, lme4: Linear mixed-effects models using Eigen and S4. R package version 1.1-7, URL: http://CRAN.Rproject. org/package $=$ lme4.

Bokdam J. \& Gleichman M., 2000, Effects of grazing by free-ranging cattle on vegetation dynamics in a continental north-west European heathland, Journal of Applied Ecology, 37: 415-431.

Cummins R.P. \& Miller G.R., 2002, Altitudinal gradients in seed dynamics of Calluna vulgaris in eastern Scotland, Journal of Vegetation Science, 13: 859-866.

Lake S., Bullock J.M. \& Hartley S., 2001, Impacts of livestock grazing on lowland heathland in the UK, English Nature Research Reports no 422, Peterborough, UK. 
Mitchell R.J., Rose R.J. \& Palmer S.C.F., 2008, Restoration of Calluna vulgaris on grass-dominated moorlands: The importance of disturbance, grazing and seeding, Biological Conservation, 141: 2100-2111.

Newton A.C., Stewart G.B., Myers G., Diaz A., Lake S., Bullock J.M. \& Pullin, A.S., 2009, Impacts of grazing on lowland heathland in north-west Europe, Biological Conservation, 142: 935-947.

Piessens K., Honnay O. \& Hermy M., 2005, The role of fragment area and isolation in the conservation of heathland species, Biological Conservation, 122: 61-69.

Pons T.L., 1989, Dormancy and germination of Calluna vulgaris (L.) Hull and Erica tetralix L. seeds, Acta Oecologica, Oecologia Plantarum, 10: 35-43.
Sedláková I. \& Chytrý M., 1999, Regeneration patterns in a Central European dry heathland: effects of burning, sod-cutting and cutting, Plant Ecology, 143: 77-87.

Valbuena L., Tárrega R. \& Luis-Calabuig E., 2000, Seed banks of Erica australis and Calluna vulgaris in a heathland subjected to experimental fire, Journal of Vegetation Science, 11: 161-166.

Vera M.L., 1997, Effects of altitude and seed size on germination and seedling survival of heathland plants in north Spain, Plant Ecology, 133: 101-106. 